\title{
Diagnóstico y tratamiento de la lepra
}

\author{
Francisco Javier López-Antuñano, M.D., M.P.H. ${ }^{(1)}$
}

$\mathrm{L}$ a lepra es una de las enfermedades del hombre que ha sido reconocida por antiguas culturas desde el año 1400 a.C. Esta revisión engloba el conocimiento actual de factores intrínsecos que influyen en la resistencia a la infección por Mycobacterium leprae, en la regulación de la variedad de manifestaciones clínicas y patológicas y en la respuesta inmune dentro del amplio espectro de la enfermedad, desde el polo tuberculoide (paucibacilar), hasta el lepromatoso (multibacilar). Se discuten la especificidad, la sensibilidad y la utilidad de los métodos disponibles de diagnóstico para la identificación y la clasificación de los bacilos ácido-alcohol resistentes; la detección de antígenos específicos en la piel, en las mucosas de la nasofaringe, en la orina y el suero, así como en la medición de anticuerpos específicos y la respuesta intradérmica a extractos de bacilos. Hasta el momento, la única medida efectiva de control que ha disminuido sustancialmente el número de casos registrados es la poliquimioterapia (PQT). Se concluye que la eliminación de la lepra en el continente americano es factible de alcanzar para el año 2000 en la mayoría de los países, siempre que los sistemas nacionales de salud mantengan el compromiso de identificar, registrar y tratar todos los casos diagnosticados. Se proponen estrategias en relación con los esquemas efectivos de tratamiento, la evaluación de los programas de PQT, las actividades de coordinación y armonización con otros programas de salud pública y el desarrollo de investigación operacional.

La lepra es una enfermedad infecciosa crónica producida por M. leprae. ${ }^{1}$ Esencialmente es una enfermedad de los nervios periféricos, pero también afecta la piel y otros órganos (mucosas, ojos, testículos, tracto respiratorio alto, músculos y huesos). En la práctica sanitarista los casos de lepra se definen como: personas que tienen signos clínicos de lepra, con o sin confirmación bacteriológica o serológica del diagnóstico, y todas ellas necesitan tratamiento. Son considerados como signos clínicos cardinales de lepra los siguientes: a) lesión cutánea única o múltiple (hipopigmentada o eritematosa), no típica de alguna otra enfermedad cutánea; b) pérdida de sensibilidad (térmica, dolorosa y/o del tacto) con o sin lesión cutánea, y c) troncos nerviosos o nervios cutáneos engrosados. Son considerados equivalentes de los signos cardinales: a) la presencia de bacilos ácido-alcohol resistentes en frotis o biopsias de piel, y b) la evidencia histopatológica definida de lepra, confirmada por un dermatólogo con experiencia en la enfermedad.

Se consideran como sospechosos de lepra los casos donde se encuentra apenas uno de los signos cardinales (o equivalente) de los anteriormente mencionados. Se definen como lepra incipiente cuando están presentes dos signos cardinales (o equivalentes), representados por un número limitado de lesiones, en ausencia de discapacidades. El de lepra avanzada se define cuando las lesiones son extensas y/o hay discapacidades. Para comprender mejor las bases, la disponibilidad y la factibilidad de utilización de los métodos disponibles para el diagnóstico de la lepra, conviene revisar algunos aspectos del conocimiento actual sobre la respuesta inmune del hospedero, el espectro clínico de la enfermedad y los genes y antígenos del bacilo.

\section{Respuesta inmune y espectro clínico}

Los pacientes que presentan fuerte respuesta inmune celular desarrollan la forma localizada de la enfermedad, su sistema inmune es capaz de destruir gran número de bacilos, y la enfermedad es paucibacilar; estos pacientes se encuentran en el polo tuberculoide (TT) del espectro (lesiones granulomatosas). En el polo opuesto, en la lepra lepromatosa (LL), la reactividad específica inmune celular está prácticamente ausente, por lo que los bacilos se multiplican en los macrófagos

(I) Centro de Investigación en Salud Poblacional, Instituto Nacional de Salud Pública, México. 
y en otras células; la enfermedad es multibacilar, se infiltra en los nervios periféricos y se extiende a casi toda la piel. Las células leprosas o espumosas contienen gran número de bacilos y se acumulan para formar nódulos. Entre esos dos polos opuestos existe un amplio espectro de manifestaciones limítrofes en la línea de borde (BT y BL). El grupo de casos indeterminados usualmente presentan una o varias manchas hipopigmentadas siempre hipoestésicas y anhidróticas, y se les considera como la forma más temprana de la enfermedad. Más de las dos terceras partes de las personas infectadas pueden curarse espontáneamente; algunas permanecen en el mismo estado paucibacilar y progresan hacia las formas BT, BL y LL. ${ }^{2}$

Hay dos tipos de reacción del aparato inmune al M. leprae. La reacción tipo 1 se debe a cambios rápidos en la respuesta inmune mediada por células (RIMC), hacia uno u otro de los extremos del campo limítrofe o dimorfo del espectro, $y$ ha sido etiquetada como lepra de respuesta inmune inestable, o sea, la lepra de la línea de borde entre el polo tuberculoide (BT) y el polo lepromatoso (BL). Esta reacción de degradación recuerda el principio inmunológico de que la carga antigénica es directamente proporcional al efecto depresor de la RIMC. Por el contrario, el efecto en reversa o de mejoría del polo BL al BT y la eliminación del agente causal se han documentado después de la quimioterapia antileprosa efectiva. La reacción tipo 2 es una respuesta humoral, es decir, una reacción antígenoanticuerpo que involucra al complemento. Ocurre casi exclusivamente en la LL y, ocasionalmente, en la BL. Se identifican nódulos (erythema nodosum leprosum, ENL) y generalmente hay evidencia de manifestaciones sistémicas y tóxicas. ${ }^{3}$

\section{Genes y antígenos}

La resistencia del huésped humano a la infección por M. leprae está influida por factores genéticos, lo cual explica el espectro clínico y patológico tan variado de la enfermedad. La capacidad de los macrófagos para detener la multiplicación de las micobacterias varía mucho, pero no se conoce con precisión la función del gene que expresa y determina la capacidad bacteriostática en los macrófagos. Las moléculas de clase HLA II intervienen en la respuesta específica a la infección y en la evolución de la respuesta inmune secundaria a los antígenos de M. leprae. Los sistemas HLA que controlan la inmunidad mediada por células hacen probable que las diferencias en los haplotipos HLA contribuyan al amplio espectro de respuesta inmune observada en la lepra. Debido a la complejidad de los factores de riesgo intrínsecos de la susceptibilidad o resistencia a la lepra, no se han descrito los determinantes genéticos con precisión, pero se asume que por lo menos dos loci pueden contribuir a la transmisión del M. Leprae, junto con los eventos ambientales ligados a la duración y la intensidad de factores de riesgo extrínsecos, variando en función del tiempo. En general, los isotipos HLA-DR están asociados con respuesta protectora, mientras que los isotipos HLA-DQ están asociados con las formas multibacilares de la lepra lepromatosa. ${ }^{4}$

La relación entre la carga antigénica, el tipo de reacción inmune y la presencia de neuritis, probablemente no es exclusiva de la LL. La activación de linfocitos $\mathrm{T}$ autorreactores con especificidad para compartir epítopos podría contribuir a daño neural en lepra TT, la cual se caracteriza por ausencia o escasez de $M$. leprae en células de Schwann. Steinhoff y colaboradores ${ }^{5}$ demostraron en ratones que las células T CD8+ reconocen y lisan las células de Schwann que presentan el antígeno de $M$. leprae en el contexto de los productos del gene clase I del complejo mayor de histocompatibilidad (MHC). Como las células Schwann de murinos son clase I negativas, la presentación del antígeno requiere estímulo previo con interferón- $\gamma$ (IFN- $\gamma$ ). Las células TCD8+, activadas contra fragmentos trípticos de la proteína HSP $65 \mathrm{kD}$ (heat shock protein) micobacteriana, reconocen los epítopos de la propia HSP 65 kilodaltones $(\mathrm{kD})$, los cuales se generan por medio del proceso metabólico de la clase I citoplásmica. También son capaces de lisar las células de Schwann que han sido activadas por el INF- $\gamma$ y no iniciadas con péptidos HSP 65kD. La clase I (H-2D) restringe linfocitos T CD8+ $\mathrm{a} / \mathrm{b}$ con especificidad para la HSP $65 \mathrm{kD}$ micobacteriana y reconoce a las células Schwann estimuladas con INF- $\gamma$, probablemente porque son específicas para uno o varios epítopos compartidos por la HSP $60 \mathrm{kD}$ bacteriana y un antígeno de reacción cruzada del huésped.

El antígeno mejor reconocido por los linfocitos $\mathrm{T} C D 4+$ que reaccionan con perfiles de linfocinas y funciones efectoras consistentes de inmunidad protectora es la HSP $60 \mathrm{kD}$. La presencia de un gran número de epítopos en las células T presentados por varias moléculas de HLA clase II hace a este antígeno relevante para el diseño de una subunidad inmunógena. Sin embargo, se ha sugerido que la HSP 60kD bacteriana podría inducir condiciones para autoinmunidad. La expresión HLA-DR4 representa un factor de riesgo en el hombre para algunas enfermedades autoinmunes. Estas observaciones sugieren que los epítopos HSP $60 \mathrm{kD}$ micobacterianos presentados a las células T en el contexto de la expresión HLA-DR4 pueden ser relevantes en el desarrollo de autoinmunidad. En total, 
se han reconocido cinco epítopos en el contexto del HLA-DR4 por HSP $60 \mathrm{kD}$ de $M$. leprae reactivo a clonas de linfocitos CD4+ de personas inmunizadas con $M$. leprae. Dos de los epítopos fueron específicos de M. leprae (aa 343-355, aa 522-534), mientras que otros tres epítopos eran comunes a M. leprae y $M$. tuberculosis (aa 331-345, aa 441-455, aa 501-515). No obstante, todos estos epítopos pertenecen a las regiones altamente divergentes entre la HSP 60 micobacteriana y la secuencia homóloga de la HSP 60 humana, lo cual sugiere que los linfocitos que reconocen la HSP 60 micobacteriana en el contexto del HLA-DR4 no necesariamente pueden inducir autoinmunidad. ${ }^{6}$

El $69 \%$ de pacientes con lepra tuberculoide sin tratamiento son positivos a otro antígeno de $35 \mathrm{kD}, \mathrm{y}$ $45 \%$ de esos pacientes muestran anticuerpos anti-35 kD. Se observa consistentemente mayor tasa de positividad a los antígenos de 35, 12 y 30 a 40 kD, componentes de $M$. leprae, en pacientes con lepra lepromatosa que en pacientes con lepra tuberculoide. Durante el curso de la terapia la tasa de positividad al antígeno disminuye gradualmente, y el antígeno no se encuentra en los pacientes con lepra indeterminada. Como el antígeno está presente presumiblemente en exceso antes de que se formen los anticuerpos, este enfoque experimental para detectar antígeno podría ser útil para el diagnóstico de la lepra. El ensayo inmunorradiométrico es simple, seguro y sensible a nivel de nanogramo para demostrar antígeno de $M$. leprae en suero, usando anticuerpos específicos y de reacción cruzada. ${ }^{7}$

El glicolípido fenólico - 1 (PGL-1) es otro antígeno específico de $M$. leprae y se puede medir en la orina para el diagnóstico y la evaluación de la quimioterapia contra la lepra. El ensayo para detectar este antígeno es simple y tiene especificidad de $100 \%$, pero su sensibilidad varía con el tipo de lepra: 92\% para LL, 56\% para BL y $18 \%$ para BT. Después de iniciada la quimioterapia en pacientes LL, el PGL-1 aumenta transitoriamente en la orina, seguido por una franca disminución. Durante los tres primeros meses de PQT, el nivel del PGL-1 en la orina se reduce de 1 a $10 \%$ y, con frecuencia, es imperceptible. Este ensayo parece tener gran potencial para evaluar las recaídas y las fallas en el tratamiento de pacientes con lepra. ${ }^{8}$

La prevalencia de IgM anti-glicolípido fenólicoPGL-1 en el suero de contactos familiares de pacientes con lepra, usando el método de ELISA, es muy baja ( $1.17 \%$ en Polinesia), debido a la baja prevalencia de lepra. La experiencia en el seguimiento de 1123 contactos para el diagnóstico de la infección subclínica muestra que el método es de bajo rendimiento y de costo-efectividad baja. Después de cinco años, la proporción de personas que desarrollaron la enfermedad fue el mismo entre los seronegativos que en los tres seropositivos. Sólo $17.5 \%$ de los casos nuevos de lepra encontrados tenían relación con la población encuestada. Desde el punto de vista práctico, aunque el ensayo puede contribuir al diagnóstico de la lepra, no parece ser útil en estudios epidemiológicos. ${ }^{9}$

González-Abreu y colaboradores ${ }^{10}$ probaron 3336 muestras de suero de contactos de pacientes de lepra en busca de anticuerpos antiglicolípido fenólico 1 con ELISA, usando el antígeno del disacárido sintético conjugado con albúmina bovina. La tasa de positividad total fue de $9.3 \%$. No se encontraron diferencias significativas entre un grupo de contactos familiares de pacientes lepromatosos y otro de pacientes con enfermedades distintas. La proporción de personas positivas al ELISA es un poco mayor entre los familiares en comparación con los compañeros de trabajo y los vecinos, pero significativamente diferente entre los dos últimos grupos $(p<0.05)$.

La relación entre la carga antigénica, la incidencia de reacciones tipo 1 y la neuritis es significativamente mayor entre pacientes leprosos multibacilares inmunodeprimidos, seropositivos al virus de inmunodeficiencia humana $(\mathrm{VIH})(p<0.0005)$. Por otro lado, no hay diferencia significativa entre el número de pacientes paucibacilares VIH seropositivos y seronegativos que desarrollaron estas complicaciones. Ambos grupos de pacientes, de VIH seropositivos y de VIH seronegativos, muestran respuesta similar a la terapia con esteroides para el tratamiento de la neuritis aguda. ${ }^{11}$

La patogenicidad de M. leprae es probablemente muy baja, ${ }^{12}$ y hay evidencias de que la tasa de infección excede la tasa de enfermedad. ${ }^{13}$ Esto podría hacer pensar que existen diversas fuentes de infección. Además, los pacientes multibacilares que dispersan $M$. leprae desde la nasofaringe probablemente son fuente de infección desde antes de ser diagnosticados. ${ }^{14}$ Considerando que $M$. leprae no puede cultivarse in vitro y que la coloración de bacilos ácido-alcohol resistentes (BAAR) es inespecífica y no sensible, la reacción en cadena de la polimerasa (PCR) para la identificación de secuencias específicas de ADN puede ser una alternativa válida para determinar la presencia de $M$. leprae, tanto en biopsias de piel como de isopos, con muestras de contenido nasofaríngeo de personas sospechosas, con el propósito de efectuar estudios epidemiológicos. ${ }^{15-17}$

Las lesiones en la piel son fuente básica para obtener información inmunológica y biomolecular sobre los mecanismos de la respuesta a la infección por M. leprae en el hombre. Por ejemplo, para evaluar la correlación entre subgrupos de células y mediadores inmunológicos solubles, así como para estudiar los efectos de la inoculación de linfocinas exógenas sobre 
las lesiones, con fines de diagnóstico y pronóstico, se podrían utilizar los siguientes enfoques: a) cambios espontáneos en los subgrupos de linfocitos $\mathrm{T}$ y en las cantidades de linfocinas que se presentan en la reacción inmune durante la fase aguda de la infección; b) determinación del equilibrio entre las lesiones establecidas por largos periodos y la presencia de linfocitos $\mathrm{T}$ y supresores en diferentes proporciones; c) definición del nivel de la actividad inmune en diferentes tipos de lesiones, y d) papel de las linfocinas exógenas para alterar ese equilibrio y cambiar temporalmente el panorama histológico.

\section{Antígenos compartidos entre distintas micobacterias}

La identificación de antígenos de micobacterias por medio de técnicas modernas de inmunohistoquímica, microscopía electrónica, hibridación en mancha (Dot), utilización de anticuerpos policlonales y monoclonales, ha mostrado reacciones cruzadas entre diferentes especies del mismo género de micobacterias. Los antígenos compartidos por distintas micobacterias son factores de confusión en el diagnóstico diferencial de la lepra. A continuación se presentan ejemplos relevantes de estas características.

No obstante que la detección inmunohistoquímica de antígenos de micobacterias es relativamente específica ${ }^{18}$ y puede ser muy útil particularmente en el estudio de cambios inmunopatológicos y en el diagnóstico diferencial de la lepra y la tuberculosis, experimentalmente se demostró la presencia compartida de antígenos de $M$. bovis y $M$. tuberculosis en ratones de experimentación y en pacientes tuberculosos. Además, utilizando métodos de coloración inmunohistoquímica doble como el HRP-SPA e IGSS (Horse Radish Peroxidase-Staphylococcal Proteine A e Immunogold Silver Stain), se demostró que ambos antígenos están presentes en otros BAAR, como M. leprae y micobacterias atípicas (fotocromógenos).

La microscopía electrónica muestra $M$. leprae en los fagolisosomas de los macrófagos, mientras que la microscopía inmunoelectrónica muestra marca a lo largo de las membranas de la bacteria. Los macrófagos de las lesiones de la piel de LL se colorean porque contienen $M$. leprae, el cual reacciona con anticuerpos contra M. leprae, M. tuberculosis o micobacterias atípicas en el suero humano y con anticuerpos contra M. butyricum en suero de conejos inmunizados con varios antígenos y adyuvante completo de Freund. Estos resultados indican que en los estudios inmunohistoquímicos debe usarse suero afín purificado, o bien, anticuerpos monoclonales para detectar antígenos específicos, con el fin de evitar las confusiones por acción cruzada, si se usa suero intacto policlonal. ${ }^{19}$

Se demostró la presencia de la misma secuencia repetitiva del $\mathrm{ADN}$ de $M$. bovis (BCG) y de $M$. tuberculosis, pero no está presente en $M$. leprae, $M$. kansasii, M. flavescens, M. fortuitum, M. vaccae, M. phlei, $M$. smegmatis ni en M. marinum. En M. tuberculosis esa secuencia repetitiva es polimórfica, pero no lo es en BCG. El análisis de la Dot sugiere que esta secuencia repetitiva podría utilizarse para la identificación de gérmenes patógenos del género Mycobacterium en muestras clínicas. ${ }^{20}$

Cruaud y colaboradore ${ }^{21}$ determinaron anticuerpos séricos IgG e IgM contra el antígeno 2, 3-diacyltrehalosa-2'- sulfato (SL-IV) usando ELISA en controles y en pacientes con lepra y tuberculosis. En el caso de lepra, el título del anticuerpo anti-SL-IV (IgG e IgM) aumentó desde el polo tuberculoide hasta el lepromatoso del espectro. En la población encuestada, la sensibilidad del ensayo es de $93 \%$ en lepra multibacilar y de $33 \%$ en paucibacilar, y la especificidad, de $89 \%$. Los pacientes multibacilares con ENL mostraron títulos menores que los no-ENL. Los resultados del ELISA son similares a los obtenidos cuando se usa como antígeno el glicolípido- fenólico 1 de M. leprae (PGL-I). En caso de tuberculosis pulmonar y extrapulmonar, se detectan títulos significantes de anticuerpos anti SL-VL IgG e IgM en 75\% de los pacientes al usar un punto de corte de 0.150 de absorbancia, y en $51.6 \%$ si se usa el corte a 0.300 . La especificidad es de 88 y $100 \%$, respectivamente. La determinación de anticuerpos IgG e IgM contra SL-VL es útil para un programa de búsqueda de casos en el punto de corte de 0.150 y para serodiagnóstico a un corte de 0.300 .

Tanto en sonicados de M. tuberculosis como de $M$. leprae se encuentra un antígeno de bajo peso molecular denominado L4 de naturaleza fosfolipídica, que muestra reacción cruzada al anticuerpo monoclonal IgG2a. La reacción cruzada del anticuerpo monoclonal L4 se explica por la presencia de otros epítopos semejantes L4-PIM, en sonicados de M. leprae. Los anticuerpos de clase IgG contra M. tuberculosis L4-PIM, se detectan en el suero de pacientes con lepra, sin la evidencia de reacción de linfocitos T al L4-PIM. La demostración de la correlación de los títulos de anticuerpos IgG anti-L4-PIM y anti-disacárido-conjugados con albúmina sérica de bovino IgM en el suero de pacientes con lepra, indica que la medida de anticuerpos contra L4-PIM puede usarse como ensayo complementario para la prueba con el disacárido sintético conjugado con albúmina de bovino para el diagnóstico y el seguimiento del tratamiento de los enfermos de lepra. ${ }^{22}$ 


\section{Diagnóstico}

En la práctica sanitaria, en el nivel de atención primaria de la salud, el diagnóstico de la lepra se hace por medio del examen clínico, apoyado por la presencia de $M$. leprae en las baciloscopías practicadas en mucosa nasal, lóbulo de la oreja y lesión cutánea en el estudio histopatológico de las lesiones, así como en el resultado de la lepromino-reacción. La demora con que emergen los primeros síntomas y la escasez de estudios sobre transmisión experimental de la infección impiden la medición del periodo de incubación de una manera precisa. La evolución de la respuesta inmune y de las manifestaciones clínicas tan variadas, así como la complejidad de las manifestaciones del genoma del hombre y de las micobacterias, explican las dificultades y contradicciones para disponer en la actualidad de pruebas prácticas, económicas, altamente sensibles y específicas que permitan identificar antígenos de M. leprae con fines de diagnóstico en los servicios básicos de salud.

\section{Examen directo de micobacterias}

Para obtener muestras de la dermis, se hace una pequeña incisión de la parte afectada con una hoja de bisturí esterilizada, se extiende el plasma obtenido sobre una lámina portaobjetos y se deja secar (no son útiles las muestras de dermis con sangre). Se fija éste y se colorea con el método de Ziehl-Neelsen para detectar BAAR. Se cubre el extendido con carbol fuccina por tres minutos, se calienta ( sin hervir) a $60^{\circ} \mathrm{C}$ por cinco minutos, se enjuaga y se decolora con mezcla de $1 \mathrm{ml}$ de $\mathrm{HCl}$ concentrado en $100 \mathrm{ml}$ de etanol al 70\%, a la cual se le agrega previamente $0.6 \mathrm{~g}$ de azul de metileno. Finalmente, después de enjuagar se observa al microscopio (600-800X). La densidad de los bacilos se registra como Indice de Bacilos de 1-6 + (según se observen) desde 1-10 bacilos por 100 campos, hasta más de 1000 bacilos por campo. Se puede usar fluoramina fenólica o auramina-rodamina después de la decoloración con el azul de metileno, y los bacilos pueden observarse en un fondo negro con un microscopio de fluorescencia. ${ }^{23}$

Cuando se rexamina en el laboratorio central de un programa de control de la lepra la totalidad de las muestras de piel examinadas en los laboratorios periféricos, por lo general no hay variación en los resultados negativos (especificidad 100\%), pero sí puede haberla (hasta en $92 \%$ ) en el resultado de las muestras positivas. Bajo condiciones ideales ${ }_{,}^{24}$ la concordancia intra e interobservador con los técnicos del laboratorio central es de 45 y $55 \%$ para el mismo observador y de $36 \%$ entre observadores, lo que indica la necesidad de supervisar la eficiencia y la sensibilidad del examen en los programas de prevención y control de la lepra. Además, la identificación de la especie de micobacteria por simple observación microscópica puede ser equivocada.

\section{Prueba cutánea}

La lepromina es un extracto crudo semiestandarizado de bacilos procedentes de nódulos lepromatosos, que se utiliza en una prueba cutánea para demostrar la respuesta inmune celular. Para esto, se inoculan $0.1 \mathrm{ml}$ de lepromina intradérmicamente y se examina el sitio después de 72 horas (reacción de Fernández) o 3 a 4 semanas después (reacción de Mitsuda). El diámetro de la induración producida se mide y califica como sigue: a) sin induración, negativa; b) 1-2 $\mathrm{mm}, \pm$ (dudosa); 3-5 mm, + ; > $5 \mathrm{~mm},++$; con úlcera, +++. Una reacción de Fernández positiva indica la presencia de hipersensibilidad retardada a los antígenos de $M$. leprae y sugiere infección previa. La reacción positiva de Mitsuda puede indicar que la persona ha sido expuesta a los antígenos de $M$. leprae o que ha sido capaz de montar respuesta específica mediada por células contra M. leprae, y por lo tanto, dicha reacción tiene valor pronóstico. Aunque es positiva en casos de lepra TT y BT, la prueba no se debe usar para el diagnóstico específico de la lepra en virtud de que hay respuesta cruzada con antígenos de otras micobacterias como $M$. tuberculosis y M. bovis (BCG). ${ }^{23}$

\section{Detección de antígenos}

Desde el punto de vista del diagnóstico de laboratorio y de la evaluación de la eficacia de la quimioterapia de la lepra, el único método confiable para determinar si el organismo causal $M$. leprae era viable, dependía de su crecimiento en la planta de la pata del ratón. En un intento de sustituir este método caro y demorado, se han desarrollado reacciones en cadena con polimerasa (PCR). Estos métodos dependen de la detección del $\mathrm{ADN}$, el cual es más susceptible a la degradación en células muertas que en otros componentes celulares, por lo que es un indicador más exacto de viabilidad. En el ensayo de la PCR específica para detectar el ADN de $M$. leprae en biopsias de piel de enfermos de lepra, por medio del uso de una dilución limitada (LD-PCR), se mide la concentración del ADN de M. leprae en la muestra original. La concentración de ADN guarda mayor correlación con el índice morfológico (IM) o porcentaje de bacilos vivos (técnica de coloración que distingue morfológicamente las bacterias intactas y las dañadas) que con el número de bacterias visibles o índice bacterial (IB), el cual cuenta todas las bacterias 
(vivas y muertas). En pacientes multibacilares sujetos a PQT, el IB muestra poco o ningún cambio durante el tratamiento; el número de genomas detectados por PCR se reduce drástica y paralelamente junto con el IM. La PCR se puede usar para medir la viabilidad de M. leprae, así como para evaluar individualmente los tratamientos administrados a los pacientes y los nuevos fármacos in vivo. Este método se aplica también en el diagnóstico de otras enfermedades infecciosas en las que el cultivo de los organismos causantes es muy lento o imposible de lograr. ${ }^{25}$

Plikaytis y colaboradores ${ }^{26}$ desarrollaron una PCR en dos pasos para detectar e identificar M. leprae, que no requiere del uso de sondas de hibridación con marcadores radioactivos, usando cuatro iniciadores oligonucleóticos. Este procedimiento amplificó un producto de 347 pares de bases de $M$. leprae, provenientes de muestras que contenían tres fentogramos (fg) de ADN genómico de $M$. leprae, cantidad que se encuentra en un solo bacilo. No hubo productos de amplificación con los ADN de otras 19 especies de Mycobacterium, de células de ratón o de células humanas. Se observaron productos de amplificación menores con tres especies de Mycobacterium: M. lufu M. simiae y M. smegmatis. Estos productos fueron fácilmente distinguidos del producto de $M$. leprae por el tamaño y por el patrón de corte de las enzimas de restricción. El ensayo también amplificó las secuencias buscadas en los lisados crudos de $M$. leprae aislados en biopsias de personas o animales infectados. El ensayo, desde la preparación de la muestra hasta el análisis de los datos, puede completarse en menos de ocho horas.

Hatta y colaboradores ${ }^{27}$ determinaron a los portadores de $M$. leprae en la nasofaringe por medio de la PCR específica, dos años después de una primer encuesta a la misma población. La tasa de detección de casos clínicos no cambió mucho durante los dos años, desde la introducción de la PQT. Con esta técnica fue posible medir la incidencia de casos nuevos, los que en su gran mayoría eran paucibacilares, y al mismo tiempo se demostró que la positividad en las personas analizadas no persistió durante los dos años. Las personas positivas a la PCR durante la primera encuesta fueron negativas en la segunda, lo cual sugiere que los portadores nasales son transitorios. Aunque la presencia de $M$. leprae no implica infección o excreción de bacilos, podría favorecer la expansión de la exposición.

Roche y colaboradores ${ }^{28}$ estudiaron 65 pacientes, inicialmente seropositivos para anticuerpos IgM antiglicolípido- fenólico 1 (PGL-1), midiéndoles los niveles de anticuerpos al PGL-1, lipoarabinómano (LAM) y a la proteína $35 \mathrm{kD}$ de $M$. leprae a intervalos regulares hasta 30 meses después de iniciada la PQT. Los niveles de la IgM anti-PGL-I y de anticuerpos antiproteína $35 \mathrm{kD}$ bajaron hasta 17 y $14 \%$, respectivamente, del nivel de inicio a los 24 meses. La presencia de bacterias resistentes a las drogas en un número pequeño de pacientes no tuvo influencia significante en los cambios del nivel de anticuerpos. La tasa de disminución fue similar en las distintas categorías de la enfermedad, pero permanecieron seropositivos la mayor parte de pacientes LL después de dos años de tratamiento al compararlos con los TT e indeterminados. En contraste, el promedio de los niveles de anticuerpos IgG antiLAM permanecieron estables o aumentaron. La caída en los niveles de IgM anti-PGL-1 acompaña la reducción del IB en algunos pacientes y proporciona un parámetro complementario para evaluar la respuesta a los medicamentos. La medición de IgM anti-PGL 1 para el serodiagnóstico de la lepra en contactos y familiares de pacientes en PQT puede ser muy útil para identificar y tratar otros casos. ${ }^{29}$

\section{Quimioterapia}

La XXIII Conferencia Sanitaria Panamericana ${ }^{30}$ solicitó a los gobiernos miembros y a la Organización Panamericana de la Salud/Organización Mundial de la Salud (OPS/OMS) realizar un estudio sobre la factibilidad de eliminar la lepra, como problema de salud pública, en el continente americano. La 35a. Reunión del Consejo Directivo OPS/OMS ${ }^{31}$ de la concluyó que la eliminación es factible en la región y encomendó al Secretariado de la misma que formulara un plan de acción con base en el mandato de la 44a. Asamblea Mundial de la Salud, ${ }^{32}$ cuyo objetivo es la eliminación global de la lepra para el año 2 000. La eliminación de la lepra se define como la disminución de la prevalencia a niveles que no representen un problema de salud pública, o sea, inferiores a un caso por $10^{4}$ habitantes. En octubre de 1991, las conclusiones y recomendaciones de la Conferencia para el Control de la Lepra en las Américas, con participación de la mayoría de los países endémicos de la región, establecieron líneas técnicas y estrategias para el control y la eliminación de la enfermedad, así como el consenso para la inclusión de dichas recomendaciones en este plan de acción regional..$^{33}$ De esta manera se incluyó en la PQT: a) los casos nuevos; b) los casos registrados anteriormente y con signos o síntomas de actividad clínica o baciloscópica, y c) los casos multibacilares inactivos, pero con menos de cinco años de observación.

La única medida efectiva para el control de la lepra aplicada a partir de los años ochenta ha sido la PQT. Su implementación da como resultado un descenso significativo de la prevalencia y, en ocasiones, a niveles 
compatibles con su eliminación. La racionalidad del uso de la PQT está en el hecho de que al inicio de la terapia, el medicamento actúa sobre una población mixta de $M$. leprae. Se estima que hay de $10^{10}$ a $10^{11}$ bacilos viables presentes en un caso de lepra multibacilar. Estos bacilos son en general sensibles a la rifampicina, dapsona y clofacimina, excepto tres pequeñas poblaciones de aproximadamente $10^{4}$ bacilos cada una, resistentes a cada una de las drogas. Dado el régimen PQT/OMS para casos multibacilares, la rifampicina eliminará a corto plazo la mayoría de los bacilos, incluyendo aquellos resistentes a la dapsona o a la clofacimina. Los bacilos viables remanentes sensibles a las tres drogas o resistentes a la rifampicina serán eliminados gradualmente a ritmo más lento por la actividad bactericida de la dapsona y la clofacimina.

Se estima que los pacientes paucibacilares comienzan el proceso morboso con una población menor de bacilos viables $\left(10^{6}\right)$. Es improbable que haya bacilos resistentes a menos de que se trate de un caso de resistencia primaria a la dapsona. Aunque la monoterapia con rifampicina sería suficiente para pacientes paucibacilares, existe la posibilidad de errores de diagnóstico y de clasificación, por lo que se recomienda el uso de dos drogas. Así, la combinación de tres drogas para los pacientes multibacilares y de dos drogas para los paucibacilares sería suficiente para eliminar todos los organismos vivos existentes en el paciente.

Es obvio que los regímenes de PQT son más caros que la monoterapia con dapsona. Sin embargo, se debe tener en cuenta que el tratamiento se completa en un periodo mucho más corto. Se considera que en los casos paucibacilares, el costo de la dapsona y rifampicina por seis meses es de tres dólares. Para los multibacilares, el costo del tratamiento de dos años con dapsona, rifampicina y clofacimina es de 50 dólares, y cada año adicional cuesta 25 dólares más. El costo total de ejecución de la PQT incluye otros componentes, lo que elevaría el costo total para el tratamiento de un caso a 100 dólares; no obstante, de estos 100 dólares, 50\% sería el costo de los medicamentos, y el $50 \%$ restante, el costo de los servicios, lo que incluiría la capacitación y la ejecución del tratamiento.

La logística de la distribución de medicamentos es un punto crítico en la ejecución de la PQT. Para prevenir las dificultades operativas de esta actividad, algunos países utilizan paquetes calendarizados específicos para el programa. De esta manera se evita: el uso de medicamentos equivocados; dosis incorrectas; la utilización de rifampicina con otros fines $y$, por otro lado, se facilita el inventario; se protegen los medica- mentos, y el paciente mejora el cumplimiento de su propio tratamiento.

Con la ejecución de la PQT se consiguió una reducción de cerca de $31 \%$ en la prevalencia mundial (de 5.4 millones de casos en 1985 a 3.7 millones de casos en 1990) en los últimos cinco años. Actualmente la cobertura con PQT en el ámbito mundial alcanza 55.7\%. La introducción de la PQT por la OMS en 1982 es el avance más importante en el control de la lepra desde el uso de la sulfona cuatro décadas atrás. ${ }^{34} \mathrm{El}$ número de casos de lepra se redujo de 5.37 en 1985, a 3.1 millones en 1992,35 y a menos de un millón en 1996.

Dietrich y colaboradores ${ }^{36}$ estudiaron 307 pacientes lepromatosos (LL) y en el borde (BL). Se les administró monoterapia con dapsona o uno o dos tipos de combinaciones de medicamentos. A la fase de tres años de tratamiento, siguieron cinco años de observación. La evaluación incluyó 233 pacientes que, en conjunto, sumaron 1404 años de observación. Las muestras de 13 pacientes $(5.6 \%)$ evidenciaron resistencia a la dapsona en la prueba de resistencia hecha en la planta del pie del ratón, y estos pacientes fueron evaluados separadamente. En la monoterapia con dapsona $(n=68)$ se mostró la misma tasa de cura que con la combinación de dapsona y rifampicina $(n=77)$ o el régimen con cuatro drogas: dapsona, rifampicina, isoniazida y protionamida $(n=75)$. No se encontraron diferencias significativas en la negativización de las bacterias ni entre la monoterapia y la combinación de dos drogas, o bien, la monoterapia y la combinación de cuatro drogas. La enfermedad se hizo patente seis meses después de iniciado el tratamiento en $15 \%$ de los enfermos que recibieron monoterapia con dapsona, pero no lo hizo en ninguno de los pacientes que recibieron tratamiento combinado. La enfermedad se estabilizó o fue regresiva después de uno a nueve meses de tratamiento. No hubo diferencia en el tipo o frecuencia de las reacciones. Sólo al final de la observación programada se informaron tres recaídas. Los tres regímenes de tratamiento fueron bien tolerados. La monoterapia con dapsona es altamente efectiva en el tratamiento de la lepra multibacilar, condicionada al tratamiento supervisado. Parece que los regímenes combinados, sólo aceleran la regresión de la enfermedad activa cuando se les compara con la monoterapia con dapsona.

Los esquemas de PQT recomendados por la OMS para adultos son:

- Para la lepra multibacilar, $600 \mathrm{mg}$ de rifampicina y $300 \mathrm{mg}$ de clofacimina una vez cada cuatro semanas, junto con $50 \mathrm{mg}$ de clofacimina y $100 \mathrm{mg}$ de dapsona diariamente, durante 24 meses en total. 
- Para la lepra paucibacilar, $600 \mathrm{mg}$ de rifampicina una vez cada cuatro semanas y $100 \mathrm{mg}$ de dapsona diariamente, durante seis meses en total. Los dos esquemas de PQT, administrados en la mayoría de los países del mundo, han probado ser simples, relativamente económicos, aceptados en general y han ocasionado muy pocos efectos deletéreos en los pacientes.

Continúa siendo difícil distinguir la lepra multibacilar de la paucibacilar, especialmente con muestras de mala calidad tomadas de la piel, y es casi imposible diferenciar las recaídas de la lepra paucibacilar, de reacciones demoradas revertidas. La duración del tratamiento de dos a 10 años en casos de lepra multibacilar representa una gran dificultad y, además, los pacientes de piel clara se inconforman con las manchas causadas por la clofacimina. La disponibilidad de otros medicamentos altamente bactericidas de M. leprae y la acción relativamente lenta de la rifampicina crean la necesidad de diseñar esquemas simplificados, más cortos y mejor supervisados en un futuro cercano, con PQT de segunda generación. Estos fármacos incluyen las 4-fluoroquinolonas, pefloxacin, ofloxacin y sparfloxacin, tetraciclina, minociclina y claritromicina. ${ }^{37}$ Finalmente, en áreas de baja prevalencia se considera oportuno aplicar quimioprofilaxis e inmunoprofilaxis en niños que son contactos de pacientes lepromatosos. ${ }^{38}$

\section{Conclusiones}

Situación actual y proyección. La confluencia de los siguientes factores altamente favorables, hace factible la eliminación de la lepra:

- Oportunidad epidemiológica de que la lepra está disminuyendo en muchas partes del mundo en términos de su tendencia secular.

- Oportunidad tecnológica de la PQT para curar eficazmente la enfermedad.

- Oportunidad política por el fuerte compromiso de las autoridades de salud en la mayoría de los países endémicos.

- Oportunidad para disponer de los recursos de agencias e instituciones no gubernamentales que están apoyando la PQT y la eliminación de la lepra. ${ }^{39}$

La discapacidad ajustada en años de vida (DALY, por sus siglas en inglés), en los países democráticos en desarrollo, es de 382000 en 1990 y de 128000 para el año 2020. En los países con economía de mercado esta- blecida y ex socialistas, los DALY son de 1000 y 0 , para 1990 y 2020, respectivamente. Hay varios países en el mundo que aún no consiguen la meta de un caso de lepra por 10000 habitantes. Sin embargo, en México, hasta junio de 1996, se ha conseguido abatir las tasas de prevalencia de detección de casos. En 1996 la prevalencia de lepra fue de $1.69,2.5$ y 0.6 por 10000 en el mundo, en el continente americano y en México, respectivamente. Para lograr la meta se requiere especial impulso a la investigación operativa en los sistemas de salud, incluyendo el área epidemiológico/social, para la aplicación práctica y a corto plazo de acciones específicas que aumenten las coberturas de $90.3 \%$ en el mundo, $75.6 \%$ en el continente americano y de $69.8 \%$ en México (1996) ${ }^{40,41}$

Evaluación. En la medida en que progrese el proceso de eliminación de la enfermedad, las actividades de programación harán énfasis fundamentalmente en la vigilancia y la evaluación de los programas, lo que deberá incluir aspectos relacionados con el diagnóstico clínico y de laboratorio, así como estudios de prevalencia sobre la resistencia de $M$. leprae a los medicamentos utilizados en el tratamiento. La vigilancia y la evaluación deben realizarse con base en los indicadores epidemiológicos generados por el Sistema Nacional de Salud.

Articulación con otros programas. Además de la articulación entre los servicios con diverso nivel de complejidad del Sistema Nacional de Salud en cada país, conviene mantener la articulación intersectorial (educación, ciencia y tecnología, y medios de comunicación). La cooperación de OPS/OMS, ha intentado incrementar la articulación con otros programas regionales (Tuberculosis, SIDA, Programa Ampliado de Inmunización), en especial en actividades de capacitación de personal, logística de la provisión de drogas y otros. Con los programas de Situación de Salud y Análisis de Tendencia y de Desarrollo de Servicios de Salud se propone, respectivamente, un trabajo articulado para la estructuración e implantación de un Sistema Integrado de Información y Vigilancia Epidemiológica en Lepra y la promoción conjunta de investigaciones operacionales, hasta lograr la integración rápida y efectiva de las actividades de control/eliminación de la lepra en los sistemas de servicios generales de salud.

Desarrollo de la investigación. Es importante dar impulso especial a la investigación operativa en los sistemas de salud, incluyendo el área epidemiológico/social, con 
miras a lograr resultados, en lo posible, de aplicación práctica y a corto plazo; algunos ejemplos de los campos de investigación identificados son:

- Búsqueda de alternativas para captación amplia y oportuna de casos de lepra y seguimiento de casos bajo tratamiento con PQT.

- Estudio de factores que impiden la regularidad en el cumplimiento de los esquemas de PQT.

- Identificación de factores económicos, sociales y culturales de riesgo que favorecen la transmisión de la lepra o el fracaso de la PQT.

- Evaluación de la sensibilidad, la especificidad y la confiabilidad de los métodos de diagnóstico.

- Estudio de otras opciones para el tratamiento eficaz y generación de alternativas para la prevención de la lepra.

\section{Referencias}

I.Vogelsang TM. Gerhard Hennk Armauer Hansen 184I-I912. The discoverer of the leprocy bacillus. His life and his work. Int J Lepr Other Mycobact Dis 1978;46(3-4):257-332.

2. Jopling WH. Handbook of leprosy. 2a. edición. Londres: William Heinemann Medical Books, 1978.

3.Thangaraj RH, ed.A manual of leprocy. 6a. edición. Nueva Delhi: Printaid, 1989.

4. Lagrange PH, Abel L. The genetic susceptibility to leprosy in humans [article in french]. Acta Leprol 1996;10(I):II-27.

5. Steinhoff U, Schoel B, Kaufmann SH. Lysis of interferon- g activated Schwann cell by cross-reactive CD8+ a/b T cells with specificity for the mycobacterial $65 \mathrm{kd}$ heat shock proteine. Int Immunol 1990;2(3):279-284. 6. Mustafa AS, Lundin KE, Meloen RH, Shinnick TM, Coulson AF. Oftung FHLA-DR4-restricted T-cell epitopes from the mycobacterial $60000 \mathrm{MW}$ heat shock protein (hsp 60) do not map to the sequence homology regions with the human hsp 60. Immunology 1996;87(3):42I-427.

7. Patil SA, Girdhar BK, Singh KP, Sengupta U. Detection of mycobacterium leprae antigens in the sera of leprosy patients by sandwich immunoradiometric assay using monoclonal antibodies. J Clin Microbiol 1990;28(I2):2792-2796.

8. Mahon AC, Nurlign A, Kebede B, Becx-Bleumink M, Lefford MJ. Urinary phenolic glycolipid I in the diagnosis and management of leprosy. J Infect Dis 1991;163(3):653-656.

9. Saad MH, Medeiros MA, Gallo ME, Gontijo PP, Fonseca LS. IgM immunoglobulins reacting with the phenolic glycolipid-I antigen from Mycobacterium leprae in sera of leprosy patients and their contacts. Mem Inst Oswaldo Cruz 1990;85(2): 191-194.

10. González-Abreu E, Mora N, Pérez M, Pereira M, Pérez J, González AB. Serodiagnosis of leprosy in patients' contacts by enzyme-linked immunosorbent assay. Lepr Rev 1990;6I(2): I45-I50.

I I. Bwire R, Kawuma HJS.Type I reactions in leprocy, neuritis and steroid therapy: Impact of the human immunodeficiency virus. Trans R Soc Trop Med Hyg 1994;88:315-316.

12. Fine PEM. Leprosy:The epidemiology of a slow bacteria. Epidemiol Rev 1982;4:161-188.

13. Ulrich M, Smith PG, Sampson C, Zúñiga M, Centeno M, García V et al. IgM antibodies to native glicolipid-I in contacts of leprocy patients in
Venezuela: Epidemiological observations and a prospective study of the risk of leprocy. Int J Lepr Other Mycobact Dis 1991;59(3):405-415.

14. Klatser PR, Van Beers S, Madjid B, Day R, De Wit MYL. Detection of Mycobacterium leprae nasal carriers in population for which leprocy is endemics. J Clin Microbiol 1993;31:2947-295I.

I5. De Wit MYL, FaberWR, Krieg SR, Douglas JT, Lucas SB, Montreewasuat $\mathrm{N}$ et al. Application of a polymerase chain reaction for the detection of Mycobacterium leprae in skin tissues. J Clin Microbiol 1991;29:906-910.

16. De Wit MYL, Douglas JT, McFadden J, Klatser PR. Polymerase chain reaction for detection of Mycobacterium leprae in nasal swab specimens. J Clin Microbiol 1993;31:502-506.

17. Gillis TP, Williams DL. Polymerase chain reaction and leprocy. Int J Lepr 1991;59:3।I-316.

18. Luo D. [Immuno histo chemical demonstration of mycobacterial antigen] Chung Hua-Chieh Ho Ho Hu Hsi Tsa Chih 1990; 13(6):360-362, 38I-382.

19. Kahn HJ, Thorner P, Baumal R, Yeger H, Bailey D, Marks A. Immunohistochemical staining of macrophages in the skin lesions of leprocy: The role of antibody to mycobacteria in human serum and various polyclonal immune rabbit antisera. Histochem J 1985; 17(9): 1009-1020.

20. Franco R, Ruiz-Trevisan A, Zorzopulos J. Construccion de sondas moleculares para el diagnóstico de micobacterias. Rev Argent Microbiol 1989;2I(3-4): I 146-1 48.

21. Cruaud P, Yamashita JT, Casabona NM, Papa F, David HL. Evaluation of a novel 2,3-diacyl-trehalose-2'-sulphate (SL-IV) antigen for case finding and diagnosis of leprocy and tuberculosis. Res Microbiol 1990; I I I (6):679694.

22. Fournie J], Mullins RJ, Basten A. Isolation and structural characteristics of a monoclonal antibody-defined cross-reactive phospholipid antigen from Mycobacterium tuberculosis and Mycobacterium leprae. J Biol Chem 1991;266(2):1211-1219.

23. Bryceson A, Pfaltzgraff RE. Medicine in the tropics. Leprocy. 2a edición. Edinburg Londres: Churchill Livingstone, 1979.

24. Abraham B, Cariappa A. Inter- and intra-laboratory variation in the reporting of skin smears in leprosy. Int J Lepr Other Mycobact Dis 1991;59(I):76-81.

25. Jamil S, Keer JT, Lucas SB, Dockrell HM, Chiang TJ, Hussain R et al. Use of polymerase chain reaction to assess efficacy of leprosy chemotherapy. Lancet 1993:342:264-268.

26. Plikaytis BB, Gelber RH, Shinnick TM. Rapid and sensitive detection of Mycobacterium leprae using a nested-primer gene amplification assay.J Clin Microbiol 1990;28(9):1913-1917.

27. Hatta M,Van Beers SM, Madjid B, Djumadi A, De Wit MYL, Klatser PR. Distribution and persistence of Mycobacterium leprae nasal carriage among the population in which leprocy is endemic in Indonesia. Trans R Soc Trop Med Hyg 1995;89(4):381-385.

28. Roche. Serological monitoring of the response to chemotherapy in leprosy patients. Int J Lepr Other Mycobact Dis 1993;61:35-43.

29. Chanteau S, Cartel JL, Spiegel A, Plichart R, Roux J. La detection des IgM anti-PGLI pour le serodiagnostic des malades hanseniens et la surveillanc des sujets contacts en Polynesie Bilan sur 5 ans. Bull Soc Pathol Exot Filiales 1990;83(5):649-657.

30. Organización Panamericana de la Salud/Organización Mundial de la Salud. Conferencia Sanitaria Panamericana. Washington, D.C.: OPS/OMS, 1990.

31. Organización Panamericana de la Salud/Organización Mundial de la Salud. 35a. Reunión del Consejo Directivo OPS/OMS. Washington, D.C.: OPS/OMS, 1991.

32. Organización Panamericana de la Salud/World Health American. Leprocy resolution 44.9, Fourty fourth World Health Assembly, I3 May. Ginebra: OMS/WHA, 1991.

33. Organización Panamericana de la Salud/ Organización Mundial de la Salud, Secretaría de Salud. Conferencia sobre Lepra en las Américas. México, D.F.: OPS/OMS, SSA, 1991 octubre. 
34. World Health Organization. Chemotherapy of leprocy for control programmes. Ginebra: Report of a WHO Study Group, 1982.

35. World Health Organization. Progress toward eliminating leprocy as a public health problem. Wkly Epidemiol Rec 1994;69:145-151.

36. Dietrich M, Gaus W, Kern P, Meyers WM. An international randomized study with long-term follow-up of single versus combination chemotherapy of multibacillary leprocy. Antimicrob Agents Chemother 1994;38:22492257.

37. World Health Organization. Chemotherapy of leprocy. Report of a WHO Study Group. World Health Organ Tech Rep Serv 1994;847: I-24.
38. Waters MF. Chemotherapy of leprocy-current status and future prospects. Trans R Soc Trop Med Hyg 1993;87:500-503.

39. World Health Organization. Investing in health research and development. Report of the Ad Hoc Committee on Health Research Relating to Future Intervention Options. Ginebra:WHO, 1996; I: I33-185. 40. World Health Organization. Action Programme for the Elimination of Leprocy Status Report 1996 WHOI/LEP/96.5, Ginebra, Suiza.

4I. Secretaría de Salud. Manual de procedimientos operativos para el control de la lepra. México, D.F.: Subsecretaría de Servicios de Salud, Dirección General de Medicina Preventiva, 1996:53-58. 